\title{
Home-based preoperative rehabilitation (prehab) to improve physical function and reduce hospital length of stay for frail patients undergoing coronary artery bypass graft and valve surgery
}

\author{
lain Waite ${ }^{1,2^{*}} \mathbb{D}$, Ranjit Deshpande ${ }^{2}$, Max Baghai ${ }^{2}$, Tania Massey², Olaf Wendler ${ }^{2}$ and Sharlene Greenwood ${ }^{3,4}$
}

\begin{abstract}
Background: Evidence suggests that elective cardiac patients are at risk of functional and psychological deterioration in the time preceding surgery. This poses a risk to successful post-operative rehabilitation. This prospective one-group pre-test, post-test evaluation was designed to assess a clinical Pre-operative Rehabilitation (PREHAB) home-based exercise programme, to optimise pre-operative physical function and frailty in patients awaiting elective Coronary Artery By-Pass Graft (CABG) or Valve Surgery.

Method: Consenting patients awaiting cardiac surgery, with wait time $\geq 6$ weeks were referred to a Senior Physiotherapist for baseline assessment. Patients were offered PREHAB in the form of functional home-based exercise that was prescribed from baseline physical outcomes. All patients were followed up via telephone to ensure progression of exercise and any problems associated with it. This continued weekly until the patient attended Surgical Pre-assessment clinic, where all outcome measures were re-assessed.

Results: Twenty two patients, out of a total number of 36 patients seen in the surgical clinic between March 2016 and August 2016, participated in the prehab clinical evaluation. Twenty patients completed their prescribed exercises on a weekly basis prior to surgery. No adverse events or cardiac symptoms were reported as a result of the home exercise intervention. Paired t-Test analyses revealed a significant mean difference in clinical frailty score (CFS) of $-0.53 \pm 0.51$ (95\% Cl [-0.774, -0.279$], P=0.0003)$. Significant mean difference in six-minute walk test (6MWT) distance of $42.5 \pm 27$. $8 \mathrm{~m}(95 \% \mathrm{Cl}[23.840,61.251], P=0.0005), 6 \mathrm{MWT}$ walking speed of $0.5 \pm 0.4 \mathrm{kmh}(95 \% \mathrm{Cl},[0.2433,0.7567]$, $P=0.001)$, and short physical performance battery (SPPB) total score of $2.2 \pm 1.7,(95 \% \mathrm{Cl}[3.066,1.200]$, $P=0.0002)$ were also observed. The change in $6 \mathrm{MWT}$ distance was shown to be significantly associated with hospital length of stay (LOS) $(r=0.7 ; P=0.03)$.

Conclusion: This small exploratory evaluation suggests that providing a home-based PREHAB programme for frail patients undergoing $C A B G$ or Valve surgery may be able to improve functional ability and reduce hospital length of stay for those patients undergoing cardiac surgery. A frailty score with greater sensitivity may be required to elucidate the influence frailty could have in reducing length of stay. A large randomised controlled study is required to reveal the potential beneficial effects of PREHAB in this patient population.
\end{abstract}

Keywords: Cardiac surgery, Rehabilitation, Prehab, Frailty, Length of stay

\footnotetext{
* Correspondence: lain.waite@nhs.net

'Department of Physiotherapy, Kings College Hospital NHS Trust, London,

England

${ }^{2}$ Department of Cardiology, Kings College Hospital NHS Trust, London,

England

Full list of author information is available at the end of the article
} 


\section{Background}

By the year 2039, it is estimated that $24.3 \%$ of the UK population will be aged 65 or over. Advancements in technology, medical treatment and improved postsurgical morbidity and mortality, means the number of older adults undergoing surgical procedures is increasing faster than the rate of the population aging [1-4]. This aging population present with greater comorbidities and frailty, in turn posing significant risk to a successful post-operative recovery. Wait times for elective cardiac surgery vary but evidence shows patients ultimately deteriorate functionally and psychologically during this period prior to surgery.

The use of frailty as a risk factor or determinant in predicting adverse postsurgical outcome is evolving $[5,6]$. Longer wait times for surgery see a trend towards deterioration in both a patients' psychological and physiological condition, suggesting that the overall condition of those awaiting cardiac surgery should be monitored continuously [7]. It's indicated that as much as $45 \%$ of patients claimed their own health had suffered along with raised levels of anxiety amongst spouses [8].

Older adults undergo surgery twice as often as their younger counterparts [9], and commonly have a lower functional reserve in many body systems, making it more difficult to atone for the stress of surgery. Consequently, they often face greater postoperative complications. $[9,10]$. Defining and categorising frailty has long created a challenge for health care professionals and researchers. Frailty can be described as a state of risk or vulnerability, a precarious balance between demands and capacity to cope and impending or current disability [11]. Frailty is considered by some to exist independently with its own pathophysiology [12], but others describe it as accelerated aging or an accumulation of age related deficits [13]. Symptoms of frailty may be present in any age group [14, 15], although are perhaps more prevalent in the older adult that is exposed to a natural decline in physical and psychological function.

The advance in modern medicine is a major contributory factor to people living longer, and an overall increase in the elderly population. This increasing number of older adults, combined with the fact that older age brings augmented comorbidities, will inevitably lead to a greater incidence of frailty and subsequent heightened surgical risk. Stresses to the patient undergoing cardiac surgery are well documented and despite ever improving medical care, post-operative medical complications are more frequent in the older population. These include increased hospital length of stay (LOS), decreased physical function and decreased health related quality of life (HRQOL). There is a need for alternative or additional approaches, for optimising physical function and post-operative recovery. Preoperative rehabilitation is a concept which has been extensively studied within the orthopaedic population and has demonstrated significant reduction in the need for post-operative rehabilitation [16]. Meta-analyses of studies investigating pre-operative exercise in patients with lung cancer shows significant increase in pulmonary function with positive increases in exercise capacity [17]. Currently, within the cardiac population there is limited research about the use of preoperative rehabilitation. The studies typically concentrate on cardiopulmonary outcomes and the utilisation of respiratory physical therapy as an intervention. These interventions have resulted in some reduction in post-operative complications, and decreased hospital LOS [18]. A study by Arthur et al., [19] investigated the use of group exercise in patients awaiting CABG and demonstrated a significant decrease in hospital length of stay, increases in health related quality of life and improved recruitment to cardiac rehabilitation. These studies included patients that were physically able to travel and attend group exercise sessions, an intervention that frail patients, who are awaiting cardiac surgery would find difficult to engage with. A recent meta-analysis conducted by Jolly et al., has shown that home-based post-operative cardiac rehabilitation is as effective as hospital-based rehabilitation [20]. To date, no studies have evaluated the use of home-based pre-operative exercise rehabilitation for frail patients awaiting cardiac surgery.

The early preoperative assessment is a fundamental exchange of information between health care professionals, patients and their families. It provides an opportunity for both sides to evaluate the level of surgical risk, discuss prospective surgical and patient-based outcomes. Early preoperative assessment may also be an ideal opportunity to identify modifiable risk factors such as frailty. The time spent waiting for cardiac surgery to be scheduled, is a period of great uncertainty for a patient. There appears to be heightened anxiety regarding the inclusion of physical activity in this time period, mainly as a result of their current cardiac condition or diagnosis [21]. A lack of engagement with any physical activity or planned exercise training, coupled with increasing levels of sedentary behaviour, can lead to physical deconditioning and an increased level of frailty. The timely identification of an increased level of frailty at the early preoperative assessment, may provide a unique opportunity to engage patients with a tailored intervention during the surgery wait time (typically 6 weeks), enabling a preoperative optimisation of functional ability, confidence, motivation and a reduced probability of post-operative complications. This exploratory clinical intervention was designed as a clinical pilot study to assess a clinical Pre-operative Rehabilitation (PREHAB) home-based exercise programme, to optimise pre-operative physical function and frailty in patients awaiting elective Coronary Artery By-Pass Graft (CABG) or Valve surgery. 


\section{Methods}

\section{Study design}

A prospective, single-centre exploratory clinical pilot designed to assess and treat patients identified as frail who have been listed for elective Cardiac Artery Bypass Graft (CABG) or Valve Surgery (VS). The pilot study aimed to explore the use of a pre-surgical rehabilitation 'PREHAB' intervention, in the form of home-based exercise therapy, with the intention to optimise pre-surgical physical function.

\section{Patients}

Patients seen in early preoperative assessment clinics were voluntarily enrolled into the prehab programme when listed for cardiac surgery. The inclusion criteria for the programme included those aged $\geq 65$ years, undergoing elective Surgery for CABG, Valve repair/replacement (via sternotomy), Transcatheter Aortic Valve Implantation (TAVI) and patients with an estimated $\geq 6$ week surgical waiting list time. Participants were excluded if they required emergent surgery (Surgery for which there should be no delay due to ongoing refractory cardiac compromise), clinical instability, decompensated heart failure not yet stabilised, and any acute process causing significant symptoms or abnormal vital signs.

\section{Outcomes and assessments.}

The main aim of this clinical pilot was to explore the potential for creating a PREHAB intervention for those patients who were frail, and awaiting cardiac surgery. Patient postsurgical length of stay (LOS) was measured by the number of days from their date of surgery to the date of their discharge home from hospital. Functional capacity was assessed using 3 independent measures including, the Duke Activity Status Index (DASI) [22], the Short Physical Performance Battery Protocol (SPPB) [23] and the 6 min walk test (6MWT) [24]. The DASI is a self-administered questionnaire that measures a patient's functional capacity. The SPPB is a test designed to measure a patient's functional status and physical performance and consists of a 3-stage balance assessment, a walking speed measure and an assessment of lower limb functional strength. The 6MWT is a submaximal exercise test to measure cardiorespiratory fitness and functional capacity. Heart rate and oxygen saturation was monitored throughout the 6MWT. Patient anxiety and depression levels were scored with the Hospital anxiety and depression scale (HADS) [25]. Body mass index (BMI) was measured in line with the formula weight $(\mathrm{kg}) /$ height ${ }^{2}\left(\mathrm{~m}^{2}\right)$. Patient Frailty status was assessed using the clinical frailty scale (CFS) with its 9 point measure 'very fit' to 'terminally ill' as seen in Fig. 1, [26]. All outcome measures were assessed at baseline, and again at pre-assessment clinic. Patient agreement to engage with a post-surgical cardiac rehabilitation programme was also recorded. An anonymised patient satisfaction questionnaire was provided for patients to evaluate their experience and understanding of the PREHAB intervention.

\section{'Prehab' intervention}

Following completion of all baseline outcome measures, a prehab exercise intervention was individually tailored by a specialist physiotherapist for each patient. All exercises were demonstrated and observed in the hospital setting, prior to patients initiating their home programme. The exercise prescription was adapted for patients of differing physical abilities and needs. Balance and strength-training exercises, with progressive levels were modelled and developed from the 'Otago exercise programme to prevent falls in older people' [27]. This is shown in Table 1 (balance exercise prescription) and Table 2 (Strength exercise prescription). Patients were encouraged to self-monitor their levels of exercise intensity using the rating of perceived exertion scale (RPE) [28] and were given an individual level at which to exercise, which was dependent on their current cardiac status, symptoms and comorbidities. Progression of strength-training exercises was determined by patient reported reduction in RPE level for $\geq 1$ week or $\geq 3$ sessions without any exacerbation of cardiac symptoms. Balance exercise levels were progressed based on patients self-reported ability to safely complete those at their current level. Patients were encouraged to keep a home exercise diary and report any problems, such as pain or discomfort, so that they could be appropriately advised with any necessary exercise alterations instigated. During telephone consultations, patients would be encouraged, and commended on their efforts.

\section{Statistical analysis}

SPSS version 20 was utilised for all analyses. Descriptive statistics, comprising of mean (SD), were used to define baseline and post intervention results. Paired sample tTests were performed to examine pre and post-test differences in CFS, weight, BMI, HADS, DASI, SPPB and $6 \mathrm{MWT}$. Pearson's rank correlation was used to examine associations between frailty, functional capacity and hospital LOS.

\section{Results}

Twenty two patients, out of a total number of 36 patients seen in the early pre-operative assessment clinic between March 2016 and August 2016, participated in the prehab clinical pilot study. $90 \%$ of patients $(n=20)$ completed their prescribed exercises $3 \times /$ week prior to surgery, with a total of 15 patients attending the surgical pre-assessment appointment prior to surgery. No adverse events or cardiac symptoms were reported as a result of the home exercise intervention. The pre-post intervention results are shown in Table 3. 


\section{Clinical Frailty Scale}

1 Very Fit - People who are robust, active, energetic and motivated. These people commonly exercise regularly. They are among the fittest for their age.

2 Well - People who have no active disease symptoms but are less fit than category 1 . Often, they exercise or are very active occasionally, e.g. seasonally.

3 Managing Well - People whose medical problems are well controlled, but are not regularly active beyond routine walking.

4 Vulnerable - While not dependent on others for daily help, often symptoms limit activities. A common complaint is being "slowed up", and/or being tired during the day.

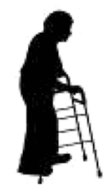

5 Mildly Frail - These people often have more evident slowing, and need help in high order IADLs (finances, transportation, heavy housework, medications). Typically, mild frailty progressively impairs shopping and walking outside alone, meal preparation and housework.

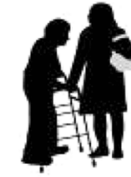

6 Moderately Frail - People need help with all outside activities and with keeping house. Inside, they often have problems with stairs and need help with bathing and might need minimal assistance (cuing, standby) with dressing.

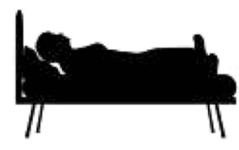

8 Very Severely Frail - Completely dependent, approaching the end of life. Typically, they could not recover even from a minor illness.

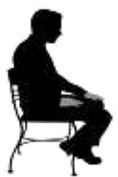

9 Terminally III - Approaching the end of life. This category applies to people with a life expectancy $<6$ months, who are not otherwise evidently frail.

\section{Scoring frailty in people with dementia \\ The degree of frailty corresponds to the degree of dementia. Common symptoms in mild dementia include forgetting the details of a recent event, though still remembering the event itself, repeating the same question/story and social withdrawal.}

In moderate dementia, recent memory is very impaired, even though they seemingly can remember their past life events well. They can do personal care with prompting.

In severe dementia, they cannot do personal care without help.

Fig. 1 Clinical Frailty Score: Canadian study on health and aging revised 2008 [22]

Paired t-Test analyses revealed a significant mean difference in CFS of $-0.53 \pm 0.51$ (95\% CI [-0.774, -0.279$]$, $P=0.0003)$. Significant mean difference in 6MWT distance of $42.5 \pm 27.8 \mathrm{~m}$ (95\% CI [23.840, 61.251], $P=0.0005), 6 \mathrm{MWT}$ walking speed of $0.5 \pm 0.4 \mathrm{kmh}(95 \%$ CI, [0.2433, 0.7567], $P=0.001)$, and SPPB total score of $2.2 \pm 1.7$, (95\% CI [3.066, 1.200], $P=0.0002)$ were also observed. The change in 6MWT distance was shown to be significantly associated with hospital LOS $(r=0.7$; $P=0.03)$. Patients improved their physical function (SPPB 30\%, 6MWT 18\%) and showed reduction in the CFS (18\%). Hospital LOS was not shown to be significantly associated with a reduction in CFS. Despite an increase in physical function, there was no significant reduction in BMI. BMI was able to be maintained in the time period ( $0.3 \%$ increase in mean body weight). Mean scores of anxiety and depression showed a nonsignificant improvement of $2.7 \%$ \& $8.5 \%$ following the intervention. Mean hospital LOS was 8.9 days. Three patients in the sample endured a prolonged LOS due to unforeseen surgical complications that were unrelated to frailty or physical function. No patient discharges were delayed due to physical or functional ability, and when the 3 patients with unrelated complications were removed from analyses, mean LOS was 5.8 days. $100 \%$ of patients were discharged back to their own home, with only 1 requiring an initial package of care for assistance with domestic tasks. $100 \%$ of participants were offered Cardiac Rehabilitation, and there was a subsequent uptake of $82 \%$. 
Table 1 Outline of the home based balance exercises given (based on Otago exercise programme balance exercises for fall prevention) [13], including levels of progression from (A) - simplest to (D) - most challenging

\begin{tabular}{|c|c|c|c|c|}
\hline \multicolumn{5}{|l|}{ Balance Exercise } \\
\hline & Level A & Level B & Level C & Level D \\
\hline Knee Bends & $\begin{array}{l}10 \text { repetitions } \\
\text { Hold support }\end{array}$ & $\begin{array}{l}10 \text { repetitions } \\
\text { No support }\end{array}$ & $\begin{array}{l}10 \text { repetitions repeat } \\
2 \text { times No support }\end{array}$ & $\begin{array}{l}10 \text { repetitions, } \\
\text { repeat } 3 \text { times No support }\end{array}$ \\
\hline Backwards Walking & 一一一一 & $\begin{array}{l}10 \text { steps, } 4 \text { times } \\
\text { Hold support }\end{array}$ & & $\begin{array}{l}10 \text { steps, } 4 \text { times } \\
\text { No support }\end{array}$ \\
\hline $\begin{array}{l}\text { Walking And Turning } \\
\text { Around }\end{array}$ & - - - - & $\begin{array}{l}\text { Walk and turn around (do a } \\
\text { figure 8) twice Use walking aid }\end{array}$ & $\begin{array}{l}\text { Walk and turn around (do a figure 8) } \\
\text { twice No support }\end{array}$ & 一二—— \\
\hline Sideways Walking & -二- & $\begin{array}{l}10 \text { steps, } 4 \text { times } \\
\text { Use walking aid }\end{array}$ & $\begin{array}{l}10 \text { steps, } 4 \text { times } \\
\text { No support }\end{array}$ & -二-二-二- \\
\hline $\begin{array}{l}\text { Tandem Stance } \\
\text { (Heel Toe Stand) }\end{array}$ & 10 s Hold support & 10 s No support & & -— \\
\hline $\begin{array}{l}\text { Tandem Walk } \\
\text { (Heel Toe Walk) }\end{array}$ & - - & -二-二-二- & Walk 10 steps Hold support, repeat & $\begin{array}{l}\text { Walk } 10 \text { steps No support, } \\
\text { repeat }\end{array}$ \\
\hline One Leg Stand & -二—— & 10 s, Hold support & $10 \mathrm{~s}$, No hold & $30 \mathrm{~s}$, No hold \\
\hline Heel Walking & 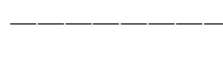 & & $\begin{array}{l}10 \text { steps, } 4 \text { times } \\
\text { Hold support }\end{array}$ & $\begin{array}{l}10 \text { steps, } 4 \text { times } \\
\text { No support }\end{array}$ \\
\hline Toe Walk & -——-— & -二-二-二- & $\begin{array}{l}10 \text { steps, } 4 \text { times } \\
\text { Hold support }\end{array}$ & $\begin{array}{l}10 \text { steps, } 4 \text { times } \\
\text { No support }\end{array}$ \\
\hline $\begin{array}{l}\text { Heel Toe Walking } \\
\text { Backwards }\end{array}$ & -——-—-— & -二-—-—- & -二-——-— & $\begin{array}{l}\text { Walk } 10 \text { steps } \\
\text { No support, repeat }\end{array}$ \\
\hline Sit To Stand & $\begin{array}{l}5 \text { stands, } 2 \text { hands } \\
\text { for support }\end{array}$ & $\begin{array}{l}5 \text { stands, } 1 \text { hand or } 10 \text { stands, } 2 \\
\text { hands for support }\end{array}$ & $\begin{array}{l}10 \text { stands, no support or } 10 \text { stands, } 1 \\
\text { hand for support, repeat }\end{array}$ & $\begin{array}{l}10 \text { stands } \\
\text { No support, repeat }\end{array}$ \\
\hline Stair Walking & As instructed & As instructed & As instructed & As instructed \\
\hline
\end{tabular}

\section{Discussion}

As an exploratory study, great importance was placed on constant re-evaluation, examining the design and procedural elements at regular intervals, considering any required changes in its template and structure. This re-evaluation promptly identified a low number of referrals from the surgical clinic, with further analysis indicating the primary reason for exclusion (55\%) to be patients having to be $\geq 65$ years of age. This specific exclusion criteria was set to identify the more frail patients and recruit a manageable quantity of patients. It was subsequently amended to enable frail patients to be referred regardless of age. This change highlighted the fact that the traits of frailty can be prevalent at varying ages [14]. As well as using this time to collect baseline information and prescribe individually specific interventions, patients had the opportunity to gain greater understanding of their pending surgery. The majority of patients referred for surgery reported a physical or psychological decline in the time leading up to their surgical clinic and admitted to having slowed down or reduced

Table 2 Outline of the home based strength exercises given, including levels of progression from (A) - simplest through to (D) - most challenging

\begin{tabular}{|c|c|c|c|c|}
\hline \multicolumn{5}{|l|}{ Strength Exercise } \\
\hline \multicolumn{5}{|c|}{$\begin{array}{l}\text { Strength Exercise } \\
\text { Level A }\end{array}$} \\
\hline Mid Row & Yellow Band & Red Band & Blue Band & $\begin{array}{l}\text { Blue Band } \\
\text { (single arm) }\end{array}$ \\
\hline \multirow{2}{*}{$\begin{array}{l}\text { Wall Push Up } \\
\text { Heel Raises }\end{array}$} & No Band & No Band & No Band & No Band \\
\hline & No Band & No Band & No Band & No Band \\
\hline Sit to Stand & $\begin{array}{l}\text { Use arms to } \\
\text { assist standing }\end{array}$ & $\begin{array}{l}\text { Arms straight } \\
\text { out in front }\end{array}$ & $\begin{array}{l}\text { Arms across } \\
\text { Chest }\end{array}$ & $\begin{array}{l}\text { Arms across } \\
\text { Chest }\end{array}$ \\
\hline Leg Abduction & No Band & No Band & Blue Band & Blue Band \\
\hline Bicep Curl & Yellow Band & Red Band & Blue band & $\begin{array}{l}\text { Blue band } \\
\text { (Single arm) }\end{array}$ \\
\hline $\begin{array}{l}\text { Seated Leg } \\
\text { Extension }\end{array}$ & No Band & No Band & No Band & No Band \\
\hline
\end{tabular}


Table 3 Pre-Post intervention results for patients completing the PREHAB programme

\begin{tabular}{|c|c|c|c|}
\hline & $\mathrm{PD}(n=)$ & $t(\mathrm{df}), P$ & $\%$ improvement \\
\hline & \multicolumn{3}{|l|}{ Mean (SD) } \\
\hline CFS & 20 & & \\
\hline Pre & $4.58(.961)$ & & \\
\hline Post & $4.05(1.177)$ & $4.472(18),<0.001$ & $11.6 \%$ \\
\hline Weight & 20 & & \\
\hline Pre & $76.05(15.67)$ & & \\
\hline Post & $76.30(15.39)$ & $-0.295(19), 0.772$ & $-0.3 \%$ \\
\hline BMI & 20 & & \\
\hline Pre & $26.10(3.57)$ & & \\
\hline Post & $26.18(3.34)$ & $-0.250(19), 0.805$ & $-0.01 \%$ \\
\hline Anxiety & 15 & & \\
\hline Pre & $6.47(4.88)$ & & \\
\hline Post & $6.33(4.70)$ & $0.274(14), 0.788$ & $2.7 \%$ \\
\hline Depression & 15 & & \\
\hline Pre & $4.73(3.97)$ & & \\
\hline Post & $4.33(3.85)$ & $1.193(14), 0.253$ & $8.5 \%$ \\
\hline SPPB (BAL) & 15 & & \\
\hline Pre & $2.87(1.302)$ & & \\
\hline Post & $3.73(.458)$ & $-3.166(14), 0.007$ & $30 \%$ \\
\hline SPPB (GAIT) & 15 & & \\
\hline Pre & $2.80(1.082)$ & & \\
\hline Post & $3.27(.799)$ & $-2.432(14), 0.029$ & $16.8 \%$ \\
\hline SPPB (CHAIR) & 15 & & \\
\hline Pre & $1.40(1.352)$ & & \\
\hline Post & $2.27(.961)$ & $-4.026(14), 0.001$ & $30 \%$ \\
\hline SPPB (TOTAL) & 15 & & \\
\hline Pre & $7.13(3.021)$ & & \\
\hline Post & $9.27(1.624)$ & $4.904(14),<0.001$ & $30 \%$ \\
\hline DASI & 15 & & \\
\hline Pre & $25.19(3.105)$ & & \\
\hline Post & $25.66(2.869)$ & $-0.437(14), 0.669$ & $1.9 \%$ \\
\hline 6MWT(Distance) & 11 & & \\
\hline Pre & $236.64(146.66)$ & & \\
\hline Post & 279.18 (126.95) & $5.068(10),<0.001$ & $18 \%$ \\
\hline 6MWT (Speed) & 11 & & \\
\hline Pre & $2.291(1.420)$ & & \\
\hline Post & $2.791(1.268)$ & $4.340(10), 0.001$ & $21.8 \%$ \\
\hline
\end{tabular}

the amount of activity they were now doing. The amount or rate of decline was understandably variable from patient to patient. However, in the majority of patients this was a rapid and significant decline leading to changes in their lifestyle. It also brought about forced adaptions in the activities of daily living, for both the patient and those around them, comparable to previous findings [8]. This self-realisation of decline may have been a contributory factor as to why so many of the enrolled patients were willing to follow the exercise intervention so rigorously. Using an anonymous patient feedback questionnaire, $90 \%$ of patients recruited to the study reported to complete the rehabilitation exercises $\geq 3$ times per week. Similar research has reported both positive [29] and inconsistent [19] levels of adherence, however there are no previous comparable studies in a frail population using an independent home based exercise as their intervention. This study demonstrated that significant improvements in functional ability and exercise capacity were achievable in those patients who completed the home-based Prehab programme, although patients' overall perceived ability, measured with the DASI, only demonstrated a minimal improvement. A single patient was identified to have anxiety and depression scores with the need for referral to clinical Psychology. Whilst there was no statistically significant change in HADS score post-intervention within this small sample, it is perhaps understandable that anxiety would remain high within a cohort of patients awaiting cardiac surgery, and this has certainly been seen in previous studies $[19,30]$. Whilst this study demonstrates that it is feasible to implement a home-based exercise intervention within a clinical real-world setting, a randomised controlled trial is warranted to assess the effect of this novel intervention. This exploratory study has several limitations. Adherence to the exercise intervention was self-reported by participants and there was a varying intervention time that was dependent on wait times between early pre-operative clinic and surgery.

\section{Conclusion}

This small exploratory study suggests that providing a real-world clinical home-based PREHAB programme for frail patients undergoing CABG or Valve surgery is feasible, and has the potential to improve functional ability and reduce hospital length of stay for those patients undergoing cardiac surgery. A frailty score with greater sensitivity may be required to elucidate the influence frailty could have in reducing length of stay. A large randomised controlled study is required to reveal the potential beneficial effects of PREHAB in this patient population.

\section{Abbreviations}

6MWD: 6 min walk distance; 6MWT: 6 min walk test; BMI: Body mass index; CABG: Coronary Artery By-Pass Graft; CFS: Clinical Frailty Score; DASI: Duke Activity Status Index; HADS: Hospital Anxiety and Depression Scale; HRQOL: Health related quality of life; IPAQ: International Physical Activity Questionnaire; LOS: Length Of Stay; PREHAB: Pre-operative Rehabilitation; RPE: Rating of Perceived Exertion; SPPB: Short Physical Performance Battery Protocol; TAVI: Trans catheter Aortic Valve Implantation; VS: Valve Surgery 


\section{Acknowledgments}

The authors would like to thank the nurses and administration team at Kings College Hospital Cardiology outpatient department for their assistance in patient recruitment from surgical clinics.

\section{Funding}

No funding was required.

\section{Availability of data and materials}

The datasets used during the current study are available from the corresponding author on reasonable request.

\section{Authors' contributions}

IW, SG and TM participated in design of the study. IW collected data throughout the study with analysis and interpretation of data completed by SG and IW. OW, $\mathrm{MB}$ and $\mathrm{RJ}$ assisted with the recruitment of all patients from surgical clinics. All authors read and approved the final manuscript and gave consent for publication.

\section{Ethics approval and consent to participate}

All participants gave individual consent to participation and for the use of all data collected during the study.

\section{Consent for publication}

Not applicable.

\section{Competing interests}

The authors declare that they have no competing interests.

\section{Publisher's Note}

Springer Nature remains neutral with regard to jurisdictional claims in published maps and institutional affiliations.

\section{Author details}

'Department of Physiotherapy, Kings College Hospital NHS Trust, London, England. ${ }^{2}$ Department of Cardiology, Kings College Hospital NHS Trust, London, England. ${ }^{3}$ Department of Physiotherapy and Renal Medicine, Kings College Hospital, London, England. ${ }^{4}$ Renal Medicine, Division of Transplantation Immunology \& Mucosal Biology, King's College London, London, England.

Received: 5 September 2017 Accepted: 19 October 2017 Published online: 26 October 2017

\section{References}

1. McGinnis SL, Moore J. The impact of the aging population on the health workforce in the United States: summary of key findings. Cah Sociol Demogr Med. 2006:46(2):193-220.

2. Klopfenstein CE, Herrmann FR, Michel JP, Clergue F, Forster A. The influence of an aging surgical population on the anesthesia workload: a ten-year survey. Anesth Analg. 1998;86(6):1165-70.

3. Alexander KP, Peterson ED. Coronary artery bypass grafting in the elderly. Am Heart J. 1997:134(5 Pt 1):856-64.

4. March LM, Cross MJ, Lapsley H, Brnabic AJ, Tribe KL, Bachmeier CJ, Courtenay BG, Brooks PM. Outcomes after hip or knee replacement surgery for osteoarthritis. A prospective cohort study comparing patients' quality of life before and after surgery with age-related population norms. Med J Aust. 1999;171(5):235-8.

5. Dasgupta M, Rolfson DB, Stolee P, Borrie MJ, Speechley M. Frailty is associated with postoperative complications in older adults with medical problems. Arch Gerontol Geriatr. 2009;48(1):78-83.

6. Makary MA, Segev DL, Pronovost PJ, Syin D, Bandeen-Roche K, Patel P, Takenaga R, Devgan L, Holzmueller CG, Tian J. Frailty as a predictor of surgical outcomes in older patients. J Am Coll Surg. 2010;210(6):901-8.

7. McCormick KM, Naimark BJ, Tate RB. Uncertainty, symptom distress, anxiety, and functional status in patients awaiting coronary artery bypass surgery. Heart Lung - J of acute crit care. 2006;35(1):34-45.

8. Mulgan R, Logan RL. The coronary bypass waiting list: a social evaluation. N Z Med J. 1990;103(895):371-2.

9. Thomas D. R Ritchie CS: preoperative assessment of older adults. J Am Geriatr Soc. 1995;43(7):811-21.
10. Brennen T, Leape L, Herbert L, Localio R, Lawthers A, Newhouse J, Weiler P, Hiatt $\mathrm{H}$. Incidence of adverse events and negligence in hospitalized patients. Results of the Harvard medical practice study I. N Engl J Med. 1991;324:370-6.

11. Kaethler Y, Molnar FJ, Mitchell SL, Soucie P, Man-Son-Hing M. Defining the concept of frailty: a survey of multi-disciplinary health professionals. Geriatr Today. 2003;6:26-31.

12. Fried $L P$, Tangen $C M$, Walston J, Newman AB, Hirsch C, Gottdiener J, Seeman T, Tracy R, Kop WJ, Burke G, MA MB. Cardiovascular health study collaborative research group.: frailty in older adults: evidence for a phenotype. J Gerontol A Biol Sci Med Sci. 2001:56(3):146-56.

13. Mitnitski AB, Graham JE, Mogilner AJ, Rockwood K. Frailty, fitness and late-life mortality in relation to chronological and biological age. BMC Geriatr. 2002:2:1.

14. Schuurmans H, Steverink N, Lindenberg S, Frieswijk N, Slaets JP. Old or frail: what tells us more? J Gerontol A Biol Sci Med Sci. 2004;59(9):M962-5.

15. Rockwood K, Mitnitski A, Song X, Steen B, Skoog I. Long-term risks of death and institutionalization of elderly people in relation to deficit accumulation at age 70. J Am Geriatr Soc. 2006;54(6):975-9.

16. Cabilan CJ, Hines S, Munday J. The effectiveness of prehabilitation or preoperative exercise for surgical patients: a systematic review. JBI Database Syst Rev Implement Rep. 2015;13(1):146-87.

17. Garciaa R, Yáñez Brageb M, Moolhuyzenc E, Grangerd C, Denehyd L. Functional and postoperative outcomes after preoperative exercise training in patients with lung cancer: a systematic review and meta-analysis. Interact Cardiovasc Thorac Surg. 2016;23:486-97.

18. Herdy A, Marcchi P, Vila A, Tavares C, Collaço J, Niebauer J, Ribeiro J. Pre- and postoperative cardiopulmonary rehabilitation in hospitalized patients undergoing coronary artery bypass surgery: a randomized controlled trial. Am J Phys Med Rehabil. 2008;87(9):714-9.

19. Arthur HM, Daniels C, McKelvie R, Hirsh J, Rush B. Effect of a preoperative intervention on preoperative and postoperative outcomes in low-risk patients awaiting elective coronary artery bypass graft surgery. A randomized, controlled trial. Ann Intern Med. 2000;133(4):253-62.

20. Jolly K, Taylor RS, Lip GYH, Stevens A. Home-based cardiac rehabilitation compared with centre-based rehabilitation and usual care: a systematic review and meta-analysis. Int J Cardiol. 2006;111(3):343-51.

21. Mooney M, Fitzsimons D, Richardson G. No more couch-potato! Patients experiences of a pre-operative programme of cardiac rehabilitation for those awaiting coronary artery bypass surgery. Eur J Cardiovasc Nurs. 2007:6(1):77-83.

22. Hlatky MA, Boineau RE, Higginbotham MB, Lee KL, Mark DB, Califf RM, Cobb FR, Pryor DB. A brief self-administered questionnaire to determine functional capacity (the Duke activity status index). Am J Cardiol. 1989;64(10):651-4.

23. Guralnik JM, Simonsick EM, Ferrucci L, Glynn RJ, Berkman LF, Blazer DG, Scherr PA, Wallace RB. A short physical performance battery assessing lower extremity function: association with self-reported disability and prediction of mortality and nursing home admission. J Gerontol. 1994:49(2):M85-94.

24. ATS Committee on Proficiency Standards for Clinical Pulmonary Function Laboratories. ATS statement: guidelines for the six-minute walk test. Am J Respir Crit Care Med. 2002;166(1):111-7.

25. Zigmond AS, Snaith RP. The hospital anxiety and depression scale. Acta Psychiatr Scand. 1983;67(6):361-70.

26. Rockwood K, Song X, MacKnight C, Bergman H, Hogan DB, McDowell I, Mitnitski A. A global clinical measure of fitness and frailty in elderly people. CMAJ. 2005;173(5):489-95.

27. Robertson MC, Campbell AJ, Gardner MM, Devlin N. Preventing injuries in older people by preventing falls: a meta-analysis of individual-level data. J Am Geriatr Soc. 2002:50(5):905-11.

28. Borg GA. Psychophysical bases of perceived exertion. Med Sci Sports Exerc. 1982:14(5):377-81.

29. Sawatzky J, Kehler D, Ready A, Lerner N, Boreskie S, Lamont D, Luchik D, Arora R, Duhamel T. Prehabilitation program for elective coronary artery bypass graft surgery patients: a pilot randomized controlled study. Clin Rehabil. 2014;28(7):648-57.

30. Furze G, Dumville J, Miles J, Irvine K, Thompson D, Lewina R. "Prehabilitation" prior to CABG surgery improves physical functioning and depression. Int J Cardiol. 2009:132(1):51-8. 